\title{
El periodismo literario de Ryszard Kapuściński
}

The literary journalism of Rysard Kapuściński

\author{
Moisés Limia Fernández \\ Universidad Jorge Tadeo Lozano \\ mlimia@gmail.com
}

\section{Forma de citar este artículo:}

Limia Fernández, M. (2019). El periodismo literario de Ryszard Kapuściński. RAEIC, Revista de la Asociación Española de Investigación de la Comunicación, vol 6, núm. 11, 246-267.

DOI: https://doi.org/10.24137/raeic.6.11.14

\section{Resumen:}

El reportaje practicado por el periodista polaco Ryszard Kapuściński (1932-2007) está considerado "entre las más emocionantes, innovadoras, y notoriamente subestimadas obras literarias de las últimas décadas" (Schiff, 1991, p. 175). Como corresponsal de periódicos, revistas y, fundamentalmente, de la Agencia de Noticias Polaca desde principios de los años 1950 hasta 1981 (cuando fue incluido, de modo no sorpresivo, en la lista negra del gobierno comunista de Polonia por motivos políticos) Kapuściński informó principalmente sobre eventos políticos acontecidos en el Tercer Mundo. Después de ser desterrado del periodismo oficial, reescribió su reportaje convencional utilizando técnicas literarias y publicó ulteriormente las mismas piezas reescritas como libros y artículos de revistas. En éstos, dijo, su objetivo era hacer "más que el 
periodismo" (Buford, 1987, p. 97). Ya en el año 2000, seis de sus libros habían sido traducidos a varios idiomas y su periodismo había aparecido reseñado en revistas americanas y en la revista británica Granta. Se argumentará en este artículo que el estilo y los métodos de reporteo encontrados en los libros de Kapuściński y en la práctica de ese periodismo posterior proporcionan un enfoque nítido al debate crítico sobre el periodismo literario al tiempo que justifican y vindican la carta de naturaleza literaria de los periodistas narrativos. Se presentará en este artículo una estrategia de uso de la teoría narrativa y de la ética epistémica para juzgar el periodismo literario.

Palabras clave: periodismo literario, reportaje, Kapuściński, periodismo narrativo

\section{Abstract:}

The reportage of Polish journalist Ryszard Kapuściński (1932-2007) has been called "among the most thrilling, innovative, and egregiously underread literary works" (Schiff, 1991: 175). As a correspondent for Polish newspapers, journals and the Polish News Agency from the early 1950s to 1981 (when he was blacklisted by Poland's communist government for political activities) Kapuściński reported primarily on political events in the Third World. After being banished from official journalism, he rewrote his conventional reportage using literary techniques and published the rewritten pieces as books and magazine articles. In these, he has said, his goal was to do "more than journalism" (Buford, 1987: 97). By 2000, six of his books had been translated to various languages, and his journalism had been referenced in the United States and in Granta. It will be argued in this article that the style and reporting methods found in Kapuściński's books and later journalism bring into a sharp focus the critical debate over literary journalism and reveal a flaw in recent attempts to legitimize the craft within journalism. A strategy of using narrative theory and epistemic ethics to judge literary journalism will be presented.

Keywords: literary journalism, reportage, Kapuściński, narrative journalism 


\section{INTRODUCCIÓN}

Escogemos la célebre obra periodístico-literaria de Ryszard Kapuściński debido a múltiples motivos. En primer lugar, su periodismo abarca el rango de temas controvertidos encontrados en grado variable en el trabajo de periodistas literarios conocidos, especialmente en los representantes del denominado new journalism norteamericano. Estos problemas incluyen: la aplicación de técnicas de escritura de ficción a sujetos reales; una fuerte voz personal en la escritura; evaluaciones subjetivas de eventos y personas; personajes compuestos; escenas fabricadas; citas directas; diálogos, pensamientos y sentimientos internos; y reporte de hechos no documentados. En segundo lugar, la postura epistemológica que sostiene el periodismo de Kapuściński refleja la que se encuentra en el periodismo literario más conspicuo y también más reciente. $\mathrm{Y}$, finalmente, han sido pocos los estudios del periodismo literario contemporáneo que han incluido escritores europeos (salvo contadas y meritorias excepciones), pues la mayoría han sido estadounidenses.

El periodismo literario, que también ha sido etiquetado como no ficción creativa, Nuevo Periodismo y periodismo artístico (entre otras muchas nomenclaturas), se caracteriza por estar escrito en una prosa elevada que aborda sobre eventos actuales y reales. Difiere del periodismo convencional de periódicos y revistas en aspectos concernientes a estilo, función, tema y epistemología (Connery, 1992). Los periodistas literarios usan el modelo narrativo y otras técnicas estilísticas generalmente asociadas con la escritura de ficción, rechazando los modelos informativos, expositivos y explicativos del periodismo convencional (ver Schudson, 1978, pp. 88-120; Adam, 1993, pp. 33-42). Entienden la función de su periodismo como la comunicación de "impresiones, ideas y emociones" basándose en "temas y motivos identificados por el escritor y revelados en los detalles de un evento o en los modales, la moral y las acciones de las personas" (Connery, 1992, p. 6). El periodismo literario también difiere del periodismo tradicional de un libro en que el primero explora un evento como significado, mientras que el segundo lo explora simplemente como un evento (Pizer, 1974; Weber, 1980). Además, los periodistas literarios ven el método artístico no solo como un estilo, sino también 
como una forma de conocimiento que es subjetiva, intuitiva, consciente de sí misma y romántica (Webb, 1974; Eason, 1982; Wilkins, 1989).

\section{VERDAD VERIFICABLE Y PERIODISMO LITERARIO}

AA Los académicos que han defendido el periodismo literario como un género literario generalmente han evitado hacer una distinción entre hechos y ficción, basando sus juicios en cambio en la cohesión narrativa, la verosimilitud y otros criterios literarios. Hellmann, por ejemplo, posiciona el periodismo literario dentro del mundo de la ficción, aceptando la definición de Frye de ficción como "prosa literaria", aunque sostiene que la falta de verificabilidad fáctica invalida una obra de periodismo literario (Hellmann, 1981). Heyne (1987, pp. 486-488) distingue entre exactitud y significado como dos tipos diferentes de verdad y sostiene que "la inexactitud no es necesariamente fatal para un texto de no ficción". Zavarzadeh (1976), que muestra tanto una frontal aversión a la categorización como un rechazo de la teoría de la correspondencia de la verdad, sostiene que todo el periodismo es ficción.

Por otro lado, los académicos que han intentado legitimar el periodismo literario como un género del periodismo, por otro lado, han articulado su esquema de clasificación en torno al criterio de verificabilidad. Connery (1992, p. xiv) sitúa el periodismo literario dentro de la tradición del periodismo, definiendo la práctica como "prosa impresa no ficticia cuyo contenido verificable se moldea y transforma en una historia o boceto mediante el uso de técnicas narrativas y retóricas generalmente asociadas a la ficción" (énfasis agregado). Connery sostiene que una cualidad fundamental del periodismo literario es que se basa en la "actualidad", o personas, lugares y eventos reales: "los detalles verificables son esenciales" (Connery, 1992, p. 6). Norman Sims (1984, pp. 1516) enumera la "precisión" como una de las características definitorias del periodismo literario (cfr. Sims y Kramer, 1995). Por su parte, Mark Kramer, docente y practicante del periodismo literario, argumenta que existe un contrato entre el periodista literario y los lectores por el que "los escritores hacen lo que parecen hacer, que es conseguir que la realidad sea lo más directa posible y no inventarla" (Sims y Kramer, 1995, p. 23). 
Wilkins (1989, p. 181) exige también verificabilidad al definir el periodismo literario como una historia "que conecta los hechos objetivos del evento con los hechos culturales de los símbolos y el mito".

Mark Kramer ha intentado codificar estándares para periodistas literarios basándose en el criterio de "precisión". Enumera los estándares como una serie de "mandamientos" en negativo: el periodista literario no debe usar "escenas compuestas, ni cronología inexacta, ni falsificación de la deriva o proporción discernible de los eventos, ni invención de citas ni atribución de pensamientos" a las fuentes a menos que las fuentes hayan dicho que habían tenido esos pensamientos (Sims y Kramer, 1995, p. 25). Los personajes tampoco deben ser totalmente inventados por el autor ni compuestos por dos o más personas reales (Sims, 1984).

Insistir en la verificabilidad para aceptar el periodismo literario en los dominios territoriales del periodismo, sin embargo, es problemático por una serie de razones. Primero, porque ignora la creciente evidencia de la ciencia y la filosofía que niega la existencia de una realidad verificable que puede describirse a través del empirismo positivista lógico y afirma, además, que la realidad está construida social y culturalmente (Kvale, 1995; Rorty, en Anderson, 1995; Berger y Luckmann, 1967; Anderson, 1995). En segundo lugar, no refleja la voluminosa evidencia de que el periodismo construye una verdad basada en convenciones culturalmente aceptadas, que en el caso del periodismo no literario a menudo contribuye a la reificación de quienes tienen la autoridad y al mantenimiento del status quo (Tuchman, 1978; Gans, 1980; Schudson, 1982; Altschull, 1984; Bennett y Edelman, 1985; Ettema, 1987; Herman y Chomsky, 1988). En tercer lugar, no puede acomodarse a la teoría narrativa dominante, la cual sostiene que cualquier imposición de la narrativa es un acto moral que resulta hasta cierto punto en una ficcionalización (White, 1978; Mitchell, 1981; Eason, 1982; Pauly, 1990). De hecho, cuando se aplica la teoría narrativa, los criterios para distinguir entre el periodismo literario verificable y el periodismo literario ficticio se resquebrajan. Y cuarto, utilizar la verificación como un estándar para el periodismo literario dibuja unos límites 
demasiado estrechos que dejanfuera del círculo a muchos escritores que se ocupan de eventos reales, escritores como Kapuściński.

Ryszard Kapuściński viola muchos de los estándares de exactitud codificados por Kramer. Las fuentes citadas extensamente en El Emperador, por ejemplo, son a menudo caracteres compuestos (Schiff, 1991). Esta es una técnica que comparte con otros periodistas literarios, incluido Joseph Mitchell, que compuso al personaje principal en Old Mr. Flood y puede haber inventado a Joe Gould en El secreto de Joe Gould (Sims, 1990). En 1972, Gail Sheehy creó un personaje compuesto para su informe sobre la prostitución (Newsweek, 1972).

Otro ejemplo del uso aparente de ficcionalización por parte de Kapuściński ocurre cuando (re)crea escenas y diálogos para describir el arresto del asesino de Shah Nasred-Din en 1896: "De vez en cuando se topan con unas chozas de arcilla donde demacrado los campesinos rodean a los viajeros polvorientos. '¿A quién lleva, señor?', preguntan tímidamente al soldado. '¿Quién?'. El soldado repite la pregunta y se muerde la lengua por un momento para aumentar el suspenso. 'Esto', dice finalmente, señalando al prisionero, 'es el asesino del Sha'” (Kapuściński, 2006, p. 18). Dado que el evento que se describe ocurrió en el siglo XIX, es dudoso que Kapuściński pudiera estar relatando hechos verificables en esta escena. Sin embargo, dado el contexto y el "aura de artificio" deliberadamente inventado de Kapuściński, su engaño es "transparente" (Schiff, 1991, p. 229). Sin embargo, esa transparencia no estaba presente en $A$ sangre fría cuando Truman Capote ficcionalizó una escena y un diálogo claves que fundamentan buena parte del libro en lo referido a una de las motivaciones de los asesinos; y esto de un escritor que insistió en que su objetivo era ser "inmaculadamente factual" (Plimpton, 1966, Heyne, 1987). Del mismo modo, George Orwell frecuentemente inventó escenas y hechos en El camino de Wigan Pier y otras obras de no ficción (Kenner, 1990). Del mismo modo, en Medianoche en el jardín del bien y del mal: Una historia de Savannah, el autor John Berendt altera la cronología y toma otras libertades con los hechos verificables (véase la nota del autor, Berendt, 1994). 
Cuando las citas están justificadas, Kapuściński ni siquiera intenta alcanzar la precisión.

“'No hago entrevistas', le dijo a un entrevistador. 'Y yo no realmente tomar muchas notas... No escribo conversaciones'” (Schiff, 1991, p. 228). Describiendo la mentalidad del emperador Haile Selassie, Kapuściński con frecuencia le atribuye pensamientos y emociones a su sujeto aunque no lo haya entrevistado jamás. En un pasaje, escribe: "El Emperador, sin embargo, no escuchó ni el gruñido aristocrático ni la universidad susurran, creyendo como lo hizo que todos los extremos son dañinos y antinaturales" (Kapuściński, 2007, p. 85). En esto, Kapuściński adopta una estrategia defendida por el periodista literario Joe McGinniss, quien argumentó en una nota de autor a The Last Brother: The Rise and Fall of Teddy Kennedy que un escritor que está inmerso en la vida de su tema no debería dudar en presentar eventos desde el punto de vista de su sujeto (McGinniss, 1993).

Además, tomando una postura de narrador omnisciente, Kapuściński frecuentemente ofrece análisis sin atribución, a menudo mediante la construcción de metáforas muy elaboradas. "El rechazo de un trasplante: una vez que comienza, el proceso es irreversible", escribe Kapuściński en El Shah. "Todo lo que se necesita es que la sociedad acepte la convicción de que la forma de existencia impuesta hace más daño que bien... No habrá paz hasta que el cuerpo impuesto y ajeno sea purgado" (Kapuściński, 2007, p. 138). En La guerra del fútbol y otros reportajes, escribe: "El silencio tiene sus leyes y sus exigencias. El silencio exige que se construyan campos de concentración en áreas deshabitadas. El silencio exige un enorme aparato policial con un ejército de informantes. El silencio exige que sus enemigos desaparezcan de repente y sin dejar rastro" (Kapuściński, 2012).

\section{RYSZARD KAPUŚCIŃSKI Y PERIODISMO LITERARIO}

El escritor y periodista polaco Ryszard Kapuściński constituye una verdadera rara avis dentro del llamado periodismo literario, cultivando una suerte de reportaje poético cercano a la fabulación, al apólogo o al cuento de carácter moral. En su estilo conjuga las técnicas documentales del reporterismo clásico con un particular ejercicio de 
observación de la realidad emparejado con la crónica, todo ello con la intención de destilar y extractar una verdad poética que vaya más allá de los tradicionales análisis canónicos de índole política, social o económica:

Kapuściński parte de una sólida base documental, a la manera de un reportero ortodoxo, pero escribe prescindiendo de las formas expresivas que caracterizan la prosa periodística convencional; no proporciona al lector identificaciones ni atribuciones completas; ni fecha el tiempo de la acción con exactitud; ni ofrece apenas datos, cifras o estadísticas; ni tampoco recrea declaraciones de fuentes institucionales cuando no son estrictamente imprescindibles. Por el contrario, somete la materia prima documental a un tratamiento que se podría definir como fabulador. Con el fin de alcanzar un conocimiento poético que vaya más allá de la mera veracidad positivista, elimina los contornos precisos de hechos y situaciones auténticas para conferirles una suerte de condición literaria que los extirpa en parte del discurso histórico y los traslada a una especie de mundo mítico, casi utópico y ucrónico. (Chillón, 1999, p. 306)

Kapuściński utiliza el rango de técnicas literarias comunes a los periodistas literarios, incluida la estructura narrativa, el diálogo, la ironía y la representación simbólica, pero la característica definitoria de su estilo es, sin lugar a dudas, su uso de la voz (Sims y Kramer, 1995). Sus libros, El Shah, sobre la revolución iraní que llevó a Jomeini al poder, y El Emperador, sobre la caída del monarca etíope Haile Selassie, por ejemplo, están organizados en torno a su búsqueda de sus respectivas historias.

La apertura de El Shah describe a Kapuściński examinando el desorden de fotografías antiguas, notas desorganizadas, cartas sin terminar, grabaciones de cassettes de entrevistas y otra documentación recopilada durante su estancia en Irán. “Ahora, con sólo pensar en poner todo en orden (porque el día en que me voy a ir) se acerca, me siento abrumado tanto por la aversión como por la profunda fatiga", escribe Kapuściński (2006: 4). El caos de su habitación refleja la confusión y la agitación en el exterior del hotel, donde se manifiestan los primeros efectos del fanatismo a raíz de la llegada al 
poder de Jomeini. Significativamente, el desorden en su habitación contiene la información que ha recopilado sobre la revolución que ha terminado recientemente: "En el piso, sillas, mesa, escritorio yacen montones de fichas, pedazos de papel, notas tan apresuradamente garabateadas y caóticas, Tengo que parar y pensar dónde anoté la oración" (Kapuściński, 2006, p. 3). El libro se desarrolla mientras revisa los artefactos de su investigación para poner la información en orden y superar su condición caótica. Organiza los hechos que ha investigado, presenciado y oído, otorgando sentido a la profusión de eventos, creando conscientemente una realidad que compartirá con el mundo.

La guerra de fútbol, que es una colección de reportajes, escrituras de viajes y memorias, está unificada por la voz autorizada de Kapuściński. Él ingresa a su libro como un personaje. Es "corresponsal extranjero", busca información, intenta llegar a lugares remotos y cerrados a los extranjeros, entrevista a fuentes, observa eventos, siente la fatiga y el miedo que experimentan los nativos de los países, escapando con vida de enfrentamientos peligrosos con soldados del gobierno y rebeldes por igual. En Tegucigalpa, Honduras, "corrí al hotel, irrumpí en mi habitación, metí un pedazo de papel en la máquina de escribir e intenté escribir un despacho a Varsovia", escribe Kapuściński en La guerra del fútbol y otros reportajes, su relato de la efímera guerra entre Honduras y El Salvador (Kapuściński, 2012). Su persona siempre está presente; vemos el mundo a través de sus ojos, experimentamos eventos a través de su subjetividad, incluso cuando el corresponsal extranjero no forma parte de la narración. 'El proyecto de ley de manutención infantil en el Parlamento Tanganyikan', por ejemplo, es principalmente una sucesión de lo que Kapuściński presenta como largas citas directas de los legisladores de Tanganyikan durante el debate sobre un proyecto de ley que requeriría a los padres de niños concebidos fuera del matrimonio para que apoyaran financieramente a estos infantes. Kapuściński permanece fuera del texto, pero él está allí, instando al lector a través de su selección, presentaciones y organización de las citas de tal modo que podemos percibir la ironía subyacente en las declaraciones: "De acuerdo con el delegado B. Akindu [Kigoma], el proyecto de ley de manutención infantil 
crearía un peligro especial para la gente adinerada, como por ejemplo los delegados al parlamento, porque las niñas embarazadas podrán proclamar falsamente que los padres de estos hijos ilegítimos son ministros del gobierno y delegados en el parlamento" (Kapuściński, 2012, p. 90). Su frase introductoria que comienza "de acuerdo a", así como la yuxtaposición de declaraciones en apoyo de la ley dan un significado irónico a la propia declaración del delegado.

El uso que hace Kapuściński de la voz autoral, en particular su crónica del proceso de presentación y creación de informes y reportajes, refleja la preocupación temática documentada por Eason (1990) en los trabajos de periodistas literarios como Joan Didion, Norman Mailer y Hunter S. Thompson, quienes describen lo que se siente al vivir en un mundo donde no hay consenso en torno a un marco de referencia para explicar "lo que significa todo" y "Ilamar la atención sobre los reportajes como una forma de unir al escritor y al lector en la creación de la realidad" (Sims, 1990, pp. 192-193). Kapuściński también invoca formas convencionales de entendimiento para subrayar la incapacidad de la comunicación tradicional para responder, en última instancia a la cautivadora pregunta: “¿Es esto real?”. Cuando informa sobre el derrocamiento del presidente argelino Ahmed Ben Bella, por ejemplo, Kapuściński señala que cuatro periódicos locales dieron cuatro versiones diferentes de lo que sucedió cuando Ben Bella fue depuesto, y afirma que las diversas versiones "son todas invenciones periodísticas" (Kapuściński, 2012, p. 97). En El Shah, la televisión iraní, como suele suceder en otros países, recuerda Kapuscinski, no comunica las ideas, las emociones y los deseos de los iraníes: "En todo el mundo, a cualquier hora, en un millón de pantallas, un número infinito de la gente nos dice algo, tratando de convencernos de algo, gesticulando, haciendo muecas, emocionándose, sonriendo, asintiendo con la cabeza, señalando con los dedos, y no sabemos de qué se trata" (Kapuściński, 2006, p. 10).

Pero el trabajo de Kapuściński revela funciones adicionales de la voz personal en el periodismo literario. La presencia autorial es esencial a la epistemología del periodismo de Kapuściński y al establecimiento de su credibilidad. Las convenciones objetivas tradicionales para crear significado social han demostrado ser poco confiables y colapsa 
la división entre lo universal y lo individual (Kvale, 1995). En el caso de Kapuściński, éste rechaza la ideología marxista-leninista (Kapuściński, 2012). Lo que queda, entonces, es una interpretación personal y subjetiva de la realidad. Como asevera Hellmann (1981, p. 8), "casi por definición, el nuevo periodismo es una revuelta del individuo contra las formas de experiencia homogeneizadas, contra las versiones monolíticas de la verdad". A menos que un periodista defienda al individuo sobre las versiones convencionales e institucionalizadas de la realidad, "un periodista simplemente coloca hechos nuevos en fórmulas antiguas. El nuevo periodista busca no solo hechos nuevos, sino también nuevas ideas y formas a través de las cuales pueda desarrollar un nuevo significado y, por lo tanto, tal vez acercarse a una verdad" (Hellmann, 1981, p. 8).

Kapuściński recuerda haber viajado por una carretera nigeriana, "donde dicen que ningún hombre blanco puede regresar vivo" porque, para él, es a través de la experiencia directa que uno puede conocer el mundo. "Conducía para ver si un hombre blanco podía [regresar vivo], porque tenía que experimentar todo por mí mismo... Tuve que hacerlo yo mismo porque sabía que nadie podría describírmelo" (Kapuściński, 2012, p. 130). En esto, Kapuściński reproduce en cierta manera los viajes por carretera de Hunter S. Thompson (ver, por ejemplo, Miedo y asco en Las Vegas: Un viaje salvaje al corazón del sueño americano, 1971) y el reportaje personal y participativo de Tim Cahill (Jaguars Ripped my Flesh: Adventure is a Risky Business, 1987) y Ted Kerasote (Navigations, 1986). Esencialmente, escribir literatura, un acto intensamente personal, en lugar de escribir un periodismo objetivo y convencional, permite a Kapuściński y otros periodistas literarios conocer el mundo de una manera diferente, quizás más profunda. Las narraciones individuales y locales se han vuelto singularmente significativas en este contexto, según Kvale (1995, pp. 18-25). Hay un valor epistemológico para un periodista, entonces, al rechazar las entrevistas con representantes de la autoridad social a favor de escuchar las historias de la vida cotidiana, hecho éste que constituye una característica definitoria de los periodistas literarios (Sims y Kramer, 1995). "El arte [el periodismo literario incluido] no es meramente una experiencia estética, sino una forma de conocer el mundo" (Kvale, 1995, p. 23). 
Kapuściński recordó que siempre estaba insatisfecho con el "periodismo directo" que envió por cable a sus editores en Polonia cuando era corresponsal en el extranjero de la Agencia de Prensa Polaca. Una vez enviada la noticia por cable, "siempre me quedé con una sensación de insuficiencia. Sólo había cubierto el evento político, y realmente no transmitía la naturaleza más profunda, y yo sentía, más verdadera de lo que estaba sucediendo... La segunda versión es lo que escribo más tarde, y eso expresa lo que realmente sentí, lo que viví, las reflexiones que rodean la simple noticia" (Buford, 1987, p. 94). Al contar historias y escribir literatura, los escritores y los lectores se unen en la constitución de la realidad y del significado (Kvale, 1995). Code (1987, p. 201) explica: “Es la comprensión [uno de los modos de conocimiento], en particular, la que tiene una fuente vital en la buena literatura". La literatura, por supuesto, también comunica el conocimiento de los hechos. "Pero, sobre todo, llegamos a comprender algo sobre los caracteres de las personas. Es este tipo de comprensión de las personas, de las experiencias y de los modos de vida y los valores que la literatura puede alcanzar y proporcionar mejor" (Code, 1987, pp. 201-202). Lo que Code llama "conocimiento por familiaridad" es lo que uno aprende de la experiencia inmediata. "Conocimiento por descripción", para Code, es lo que uno aprende del testimonio escrito o hablado. El conocimiento de la literatura, entonces, se encuentra situado entre los dos anteriores. Incluye conocimiento descriptivo, pero también, dado que la literatura muestra más de lo que dice, proporciona una experiencia indirecta, "en la que nos involucra para que la experimentemos casi directamente" (Code, 1987, pp. 206-207).

Usar la voz personal para establecer la credibilidad es un recurso del periodista literario. Se basa en la tradición periodística que considera que la información de "fuentes primarias" (documentos originales, datos recopilados empíricamente por el periodista, informes de testigos oculares) es de mayor valor que la obtenida de fuentes secundarias, y la información y la evidencia proporcionada por terceros, incluidos los funcionarios del gobierno y la policía y otras agencias de investigación (Ullmann y Colbert, 1991). Yendo aún más allá y estableciendo su persona dentro del texto, Kapuściński, como hacen otros periodistas literarios, asegura a los lectores que lo que está escrito es lo que realmente 
sucedió. "Las evidencias proporcionadas por testigos oculares... generan autenticidad" (Carey, 1987, p. xxix). Kapuściński construye credibilidad al mostrar a los lectores su proceso de reporteo, las dificultades que ha tenido para obtener información y su disposición a desafiar a las autoridades para obtener información de primera mano. En su reportaje sobre el levantamiento nigeriano, Kapuściński describe que fue rociado con benceno en una barricada construida por los rebeldes ("porque aquí queman a las personas con benceno: garantiza la incineración completa") y que fue golpeado y amenazado de muerte por hombres armados (Kapuściński, 2012, pp. 133-135). En el Congo, en varias ocasiones, escapó a la ejecución gracias a su osadía y a su ingenio, con el uso de sobornos, mediante el coraje, pero sobre todo gracias a la suerte (Kapuściński, 2012, pp. 61-84). "Hay un aspecto acumulativo de confiabilidad literaria”, explica Code. “Confiar en un escritor es no hacer ni más ni menos que lo que uno hace a lo largo de la vida para adquirir conocimiento de otras personas" (1987, p. 214). A medida que sus relatos de experiencias que pusieron en riesgo su vida se acumulan, cada una de ellos autenticando más su experiencia, uno es más propenso a creer en lo que Kapuściński escribe.

Como una cuestión de estilo, Kapuściński se establece sutilmente como el árbitro de la verdad. Da testimonio de lo que ve y experimenta, generalmente escribiendo en tiempo presente para acentuar la inmediatez de los eventos. Él ridiculiza la sabiduría convencional de los periódicos y la televisión. Ryszard Kapuściński muestra a los lectores el proceso por el que pasó para obtener información. Él devalúa las fuentes oficiales de información, a menudo presentándolas como personas sin nombre: "alguien me dijo en una conversación" (Kapuściński, 2012, p. 101) que Savak, la policía secreta iraní, “controlaba, alguien calculó, tres millones de informantes" (Kapuściński, 2006, p. 46). En respuesta a la pregunta de un entrevistador, Kapuściński reconoció que los críticos a menudo se quejan de su falta de datos verificables: "Kapuściński nunca menciona las fechas, Kapuściński nunca nos da el nombre del ministro, ha olvidado el orden de los eventos", parodió a sus críticos. "Todo eso, por supuesto, es exactamente lo que evito. Si esas son las preguntas que desea responder, puede visitar su biblioteca local, donde 
se pueden consultar periódicos y libros de referencia" (Buford, 1987, p. 95). Sin los datos verificables, por supuesto, Kapuściński se posiciona a sí mismo, a su propia credibilidad, como la única evidencia de que lo que escribe es verdad.

\section{EL PERIODISMO EN UN MUNDO DESORDENADO Y CAÓTICO}

La mezcla de hechos y ficciones de Kapuściński no tenía precedentes en la literatura periodística de la década de los setenta. Sin embargo, negar la legitimidad periodística de su trabajo sería aceptar premisas lógico-positivistas que son insostenibles, o de lo contrario sería una reivindicación del poder social que, en sí mismo, no podría ser defendido. Como Pauly (1990) ha afirmado:

La verdad del periodismo no reside en sus narrativas representacionalistas, como lo suponen tanto los periodistas como los críticos literarios. Los escritores usan códigos convencionales para transmitir la verdad, pero tales códigos son en sí mismos solo una forma de una serie más grande de ocasiones sociales durante las cuales el intérprete e interpretado se reúnen para discutir sus posiciones. . . Para ellos [la mayoría de editores, periodistas y editores] la escritura debe seguir siendo una profesión cosmopolita de tiempo completo, realizada en nombre del ciudadano por publicaciones comercialmente rentables que organizan burocráticamente las prácticas simbólicas a través de las cuales se representa una comunidad. (Pauly, 1990, pp. 123-125)

Para Pauly, las narrativas del Nuevo Periodismo de la década de 1960 eran "estilos de acción social" que "nos obligaban a reconsiderar los rituales sociales a través de los cuales los escritores podían declararse responsables en lugar de simplemente libres" (Pauly, 1990, pp. 123-124). Las aproximaciones radicales a la representación de la realidad en los trabajos de escritores como Hunter S. Thompson, Michael Herr y Kapuściński desafían conscientemente las convenciones del status quo de definir la verdad a la que lógicamente no se puede negar la legitimidad sin negar la posición política de sus mensajes. 
Las últimas obras de Kapuściński (las realizadas después de que se apartase de las convenciones exigidas por la Agencia de Prensa Polaca) son los informes de un periodista que lucha por capturar un mundo tan desordenado que las distinciones convencionales entre realidad y fábula, entre realidad y fantasía, eran frágiles y deshonestas. Asumido esto, su enfoque es intensamente individualista pero, a través de sus construcciones transparentes de la realidad, adopta una postura autoconsciente que es a la vez visionaria y necesariamente deficiente. No presenta sus informes como la única representación verdadera de la realidad, ya que deliberadamente llama la atención sobre sus deficiencias como un rastreador de la verdad. No son más que cuentas discretas a las que los lectores deben agregar otra información, informes y experiencia si quieren comprender completamente el mundo.

Cualquier intento de imponer a Kapuściński el estándar de actualidad y otros estándares tal y como los describen Sims y Kramer (1995) le negaría su derecho a desafiar una descripción monolítica de la realidad. Como ha señalado Bruner (1991, p. 12), lo que hace que el narrador innovador sea una figura tan poderosa en una cultura es que "puede ir más allá de los guiones convencionales, lo que lleva a la gente a ver los sucesos humanos de una manera fresca, nunca antes había notado o incluso soñado". Pero legitimar el estilo de Kapuściński no sería tampoco posible sin estándares. Las soluciones basadas en la teoría narrativa y la responsabilidad epistémica ofrecen una estrategia alternativa a los criterios basados en la realidad o en la actualidad.

La teoría narrativa ofrece los criterios de verosimilitud, probabilidad (¿la historia está libre de contradicciones?, ¿es creíble?) y fidelidad (¿Es la historia lógica y suena razonable? ¿Son las razones dadas 'buenas razones'? ¿Es leal a sus propios valores?) (Fisher, 1985; Heyne, 1987; Bruner, 1991). La verdad se evalúa al juzgar si la narrativa propia tiene sentido en comparación con otras narrativas conocidas y con el conocimiento no narrativo (Maclntyre, 1984). Como argumenta Bruner (1991, p. 13), "la verdad narrativa se juzga por su verosimilitud más que por su verificabilidad". La coherencia proporciona además una base para juzgar qué tan verdadera puede ser una narración. "Uno desconfía de lo que respecta a las obras donde la estructura interna 
falla con respecto a la coherencia, donde los personajes actúan demasiado 'fuera de carácter', y los eventos estiran nuestra credulidad demasiado lejos" (Code, 1987, p. 210). Bajo estos criterios, el trabajo de Kapuściński, que no promete detalles comprensibles y verificables, sino que ofrece una visión intensamente personal, a veces fabulista, se mantiene firme y coherente.

Eso no quiere decir que Kapuściński u otros escritores no puedan ser responsables de lo que escriben. Como señala Kvale (1995, p. 22), "con la pérdida de los sistemas generales de legitimación, cuando las acciones no se justifican recurriendo a algún sistema superior o idea de progreso, los valores y la responsabilidad ética de las personas que interactúan se vuelven centrales"; y Maclntyre está coincide básicamente con esta afirmación. Los individuos son responsables, afirma Maclntyre (1984, p. 195), y “siempre es apropiado pedir al agente un reporte inteligible". En este sentido, Kapuściński da testimonio de su proceso de presentación y creación de reportajes, proporciona pistas claras y ciertas sobre sus reglas básicas, discute sus acciones, reacciones y emociones. Sus técnicas y prejuicios se ponen al descubierto ante los lectores, permitiendo que cada uno juzgue su credibilidad. Kapuściński, respondiendo en el texto a un editor que desafió su credibilidad, delinea los límites de su contrato a sus lectores: "Ve ahí mismo', respondí con voz cansada, porque todavía sentía Stanleyville y Usumbura [ciudades en el Congo] en mis huesos. 'Vete y compruébalo tú mismo'. Y espero que vuelvas con vida". Desde este punto de vista, el escritor se sitúa como un agente moral independiente, responsable de lo que escribe, y los lectores, como agentes morales independientes, deben decidir independientemente si van a creerle o no.

Code (1987), una epistemóloga, aclara esta posición:

Cuando los eventos históricos reales o los personajes juegan papeles centrales en un trabajo, uno espera que la investigación se haya realizado con precisión; pero no existe una obligación clara para los escritores, dada la larga tradición de la licencia poética, de decir las cosas tal como eran antes de lo que podrían haber 
sido. Por lo tanto, es responsabilidad de los lectores asegurarse de que cualquier reclamo que realicen sea responsable. (Code, 1987, p. 214)

Los escritores, para lograr credibilidad, deben proporcionar "razones buenas e independientes" para respaldar sus afirmaciones de verdad (Code, 1987, p. 214). Más allá de las razones, el escritor debe proporcionar coherencia y verosimilitud. "Ser fiel a la vida difiere de la verdad de los hechos; es a la vez una relación más flexible y más exigente" (Code, 1987, p. 211).

El poder analítico de esta estrategia se ve cuando uno aplica sus criterios de verosimilitud, probabilidad y fidelidad a dos estilistas diferentes, Ryszard Kapuściński y Joe McGinniss. En El Shah, Kapuściński escribe en primera persona, acentúa la construcción de la realidad por parte del periodista / escritor, con frecuencia recuerda al lector que no posee todos los hechos (por lo tanto, que su versión es defectuosa), y advierte al lector que las convenciones culturales tradicionales para determinar la verdad ya no funcionan para explicar los eventos del mundo. "Podría continuar detenidamente sobre lo que he visto y vivido aquí", escribe Kapuściński al comienzo del capítulo inicial de El Shah, "pero es difícil organizar mis impresiones..." (Kapuściński, 2006, p. 4). El lector está informado, en otras palabras, de que el relato será el relato de Kapuscinski, pero necesariamente será defectuoso e incompleto. "Veo que me estoy perdiendo o he perdido algunas fotos", admite Kapuściński (2006, p. 26). Hay hechos que él no tiene. "La imagen fue recortada de un periódico, por lo que descuidadamente falta la leyenda" (Kapuściński, 2006, p. 134). El periódico, que representa las convenciones tradicionales de otorgar significados a los eventos, una vez separado de los eventos, resulta de muy poca utilidad. El lector (aquí, Kapuściński) debe proporcionar su propio significado a los eventos representados en la fotografía. Cuando las convenciones tradicionales ya no son útiles, no es inesperado que Kapuściński utilice su imaginación, su intuición y otros medios epistemológicos a su disposición. La escena imaginaria y el diálogo que Kapuściński construye en el que el asesino de un ex shah es conducido a su ejecución, por tanto, cohesiona y conserva la fidelidad a las reglas que Kapuściński ha establecido. Si bien la escena carece de verificabilidad, tiene 
verosimilitud. El reportaje que Ryszard Kapuściński ofrece a sus lectores es su testimonio personal y presencial. Su mejor evidencia es su voluntad de arriesgar su vida para obtener la historia y su determinación, como se evidencia en sus entrevistas (ver Buford, 1987), para usar el estilo literario y para comunicar los significados más profundos que percibe en los eventos. Como le replicó a su editor incrédulo, si no lo crees, vete allí tú mismo.

Kapuściński es un testigo que ha desafiado a la muerte para encontrar la verdad, pero reconoce que su versión es necesariamente defectuosa e incompleta, como lo será cualquier intento de establecer la verdad. ("Veo que me estoy perdiendo o he perdido algunas fotos", escribe.) De esta forma, Kapuściński reconoce las limitaciones de su voz singular $y$, por lo tanto, va más allá de una postura puramente individualista o existencialista. Aunque sus palabras son descaradas y un tanto inmodestas, Kapuściński invita a sus lectores a "ir allí", a comparar su reportaje con su propia experiencia personal. Además, al recordar a los lectores que sus afirmaciones de la verdad se basan en información incompleta, los alienta a cuestionar sus reportajes, a agregar a sus informes, a participar en la creación de la realidad social. En consecuencia, Kapuściński evita la práctica éticamente cuestionable de los escritores que adoptan una postura omnisciente, presentando sus hechos como absolutos e incontrovertibles.

Por el contrario, The Last Brother de McGinniss no es una cuenta en primera persona. Está escrito en tercera persona, con un narrador omnisciente, y se establece como un relato fiel a la realidad de los acontecimientos y las motivaciones en la vida de Teddy Kennedy. McGinniss usa técnicas literarias como el diálogo y la construcción escena por escena. Sin embargo, también recurre a fuentes autorizadas y nombradas como evidencia (David Burke, ayudante principal del senador Kennedy, es citado en varias ocasiones a lo largo del libro), y registra detalles minuciosos que dan la impresión de exactitud de los testigos: "El avión salió Washington a las 8:35. Normalmente, en el Aero Commander bimotor y seis asientos, el vuelo tomaría una hora y veinte minutos" (McGinniss, 1993, p. 373). Debido a esto, un lector tendrá razón al esperar que lo que está en el libro haya sido atestiguado o contado al autor. Bajo estas reglas, la atribución 
de pensamientos a Teddy Kennedy y la narración de eventos a través de los ojos de Teddy Kennedy sin que McGinniss lo haya entrevistado jamás carece de fidelidad, y las escenas imaginadas no coinciden con el resto de la narración. Cuando McGinniss es llamado a rendir cuentas, su respuesta en la nota del autor es que ha pasado tanto tiempo investigando la vida de Teddy Kennedy que se había "sumergido" en la vida política, tiene el derecho estilístico de saltar dentro de la cabeza de Teddy Kennedy. Y además, argumenta McGinniss, otros biógrafos han hecho lo mismo, por lo que es apropiado para él hacerlo también. Cada lector tiene la opción de creer en McGinniss, aceptar sus razones como "buenas razones". Sin embargo, no sería irrazonable, siguiendo las pautas de la responsabilidad epistémica de Code, que un lector desconfíe del trabajo de McGinniss, particularmente cuando sus lapsos éticos en escritos anteriores se consideran parte de su reporte Maclntyreano (ver Malcolm, 1989). El uso de la teoría narrativa y la teoría de la responsabilidad epistémica como una estrategia para evaluar los trabajos de Kapuściński y McGinniss permite que ambos libros sean etiquetados como "periodismo literario" $y$, sin embargo, también permite que cada escritor tenga altos estándares. Es una estrategia que tiene poder explicativo, descriptivo y evaluativo.

\section{CONCLUSIONES}

Ettema (1987, p. 85) sugirió que "una estrategia a la vez antigua y contemporánea para intentar mejorar [en el periodismo] a pesar de la incertidumbre epistemológica sería enmarcar la búsqueda periodística de la verdad como ejercicio de la phronesis aristotélica o de la sabiduría práctica". Esto significaría desarrollar dentro de los periodistas la capacidad de ejercer un juicio moral en situaciones individuales y darles amplia libertad a medida que aplican las virtudes necesarias, como la honestidad, la justicia y la humanidad. El trabajo de Kapuściński desafía valientemente las convenciones sociales y políticas, proyectando una contabilidad intensamente personal de eventos horrendos y cobardes, dando testimonio a través del estilo literario, así como a través del propio contenido. Su voz distintiva se convierte en su insignia de autenticidad. Las teorías de responsabilidad narrativa y epistémica ofrecen estándares 
realistas para juzgar el trabajo de un periodista de este tipo, poniendo en juego la importante interacción del escritor y el lector como medio para responsabilizar a los periodistas por sus escritos y reportajes.

\section{REFERENCIAS BIBLIOGRÁFICAS}

Adam, G. S. (1993). Notes toward a Definition of Journalism: Understanding an Old Craft as an Art Form. St Petersburg, FL: Poynter Institute for Media Studies.

Altschull, J. H. (1984). Agents of Power: The Role of the News Media in Human Affairs. New York: Longman.

Anderson, W. T. (1995). Four Different Ways to Be Absolutely Right. En W. T. Anderson (ed.), The Truth About the Truth: De-confusing and Reconstructing the Postmodern World (pp. 110-16). New York: Putnam.

Bennett, W. L. y Edelman, M. (1985). Toward a New Political Narrative. Journal of Communication, 35(4), 156-71.

Berendt, J. (1994). Midnight in the Garden of Good and Evil: A Savannah Story. New York: Random House.

Berger, P. L. y Luckmann, T. (1967). The Social Construction of Reality: A Treatise in the Sociology of Knowledge. Garden City, NY: Anchor.

Bruner, J. (1991). The Narrative Construction of Reality. Critical Inquiry, 18 (Autumn), $1-21$.

Buford, B. (1987). An Interview with Ryszard Kapuscinski. Granta, 21 (Spring), 81-97.

Cahill, T. (1987). Jaguars Ripped My Flesh: Adventure is a Risky Business. New York: Bantam.

Carey, J. (1987). The Faber Book of Reportage. London: Faber \& Faber.

Chillón, A. (1999). Periodismo y Literatura. Una relación de tradiciones promiscuas.

Bellaterra (Barcelona): Universitat Autònoma de Barcelona, Servei de Publicacions.

Code, L. (1987). Epistemic Responsibility. Hanover: University Press of New England.

Connery, T. B. (ed.) (1992). A Sourcebook of American Literary Journalism:

Representative Writers in an Emerging Genre. New York: Greenwood.

Eason, D. L. (1982). New Journalism, Metaphor and Culture. Journal of Popular Culture, 15(4), 142-9. 
Eason, D. (1990). The New Journalism and the Image-World. En N. Sims (ed.), Literary Journalism in the Twentieth Century (pp. 191-205). New York: Oxford University Press.

Ettema, J. S. (1987). Journalism in the 'Post-Factual Age'. Critical Studies in Mass Communication, 4(1), 82-86.

Fisher, W. R. (1985). 'The Narrative Paradigm: In the Beginning', Journal of Communication (Autumn), 74-84.

Gans, Herbert (1980). Deciding What's News: A Study of CBS Evening News, NBC Nightly News, Newsweek and Time. New York: Vintage Books.

Hellmann, J. (1981). Fables of Fact: The New Journalism as New Fiction. Urbana: University of Illinois Press.

Herman, E. S. y N. Chomsky (1988). Manufacturing Consent: The Political Economy of the Mass Media. New York: Pantheon Books.

Heyne, E. (1987). Toward a Theory of Literary Nonfiction. Modern Fiction Studies, 33(3), 479-90.

Kapuściński, R. (2006). El Shah. Barcelona: Anagrama. [ed. O. 1982]

Kapuściński, R. (2007). El Emperador. Barcelona: Anagrama. [ed. O. 1978]

Kapuściński, R. (2012). La guerra del fútbol y otros reportajes. Madrid: EnDebate. [ed. O. 1978]

Kenner, H. (1990). The Politics of the Plain Style. En N. Sims (ed.), Literary Journalism in the Twentieth Century (pp. 183-90). New York: Oxford University Press.

Kerasote, T. (1986). Navigations. New York: Vintage.

Kvale, S. (1995). Themes of Postmodernity. En W. T. Anderson (ed.), The Truth About the Truth (pp. 18-25). New York: Putnam.

Maclntyre, A. (1984). After Virtue: A Study in Moral Theory, 2nd edn. Notre Dame, IN: University of Notre Dame Press.

Malcolm, J. (1989). The Journalist and the Murderer. The New Yorker (13 March), 3873; y (20 March), 49-82, respectivamente.

McGinniss, J. (1993). The Last Brother: The Rise and Fall of Teddy Kennedy. New York: Simon and Schuster.

Mitchell, W. J. T. (ed.) (1981). On Narrative. Chicago: University of Chicago Press. Newsweek (1972) 'The Hooker's Boswell', 4 December, p. 61.

Pauly, J. J. (1990). The Politics of the New Journalism. En N. Sims (ed.), Literary Journalism in the Twentieth Century (pp. 110-29). New York: Oxford University Press. 
Pizer, D. (1974). Documentary Narrative as Art: William Manchester and Truman Capote. En R. Weber (ed.), The Reporter as Artist: A Look at the New Journalism Controversy (pp. 207-19). New York: Hastings House.

Plimpton, G. (1966). The Story Behind a Nonfiction Novel. New York Times Book Review (16 January), 2.

Schaefer, C. (1992). Textured Lives: Women, Art, and Representation in Modern Mexico. Tucson: University of Arizona Press.

Schiff, S. (1991). The Years of Living Dangerously. Vanity Fair, 421 (March), 175-9; 22834.

Schudson, M. (1978). Discovering the News: A Social History of American Newspapers. New York: Basic Books.

Schudson, M. (1982). The Politics of Narrative Form: The Emergence of News Conventions in Print and Television. Daedalus 111(4), 97-112.

Sims, N. (1984). The Literary Journalists: The New Art of Personal Reportage. New York: Ballantine.

Sims, N. (1990). Joseph Mitchell and The New Yorker Nonfiction Writers. en N. Sims (ed.), Literary Journalism in the Twentieth Century (pp. 82-109). New York: Oxford University Press.

Sims, N. y M. Kramer (eds) (1995). Literary Journalism: A New Collection of the Best American Nonfiction. New York: Ballantine.

Thompson, H. S. (1971). Fear and Loathing in Las Vegas: A Savage Journey to the Heart of the American Dream. New York: Popular Library.

Tuchman, G. (1978). Making News. New York: Free Press.

Ullmann, J. y J. Colbert (1991). The Reporter's Handbook: An Investigator's Guide to Documents and Techniques. New York: St Martin's Press.

RAEIC, Revista de la Asociación Española de Investigación de la Comunicación vol. 6, núm. 11 (2019), 246-267 